\title{
A Systematic Literature Review on Digital Knowledge Sharing in Higher Education
}

\author{
Gebremedhin Gebreyohans \\ Addis Ababa University \\ gereisms12@gmail.com
}

\author{
David T. Croasdell \\ University of Nevada, Reno \\ davec@unr.edu
}

\author{
Million Meshesha \\ Addis Ababa University \\ meshe84@yahoo.com
}

\begin{abstract}
Digital knowledge sharing is a common practice. It can be used by Higher Education Institutions (HEIs) to maintain education quality. While several studies have been conducted to enable academics to share their knowledge and experiences, there have been few attempts to examine the main motivators of online knowledge sharing in HEI. This research explores state of the art knowledge sharing behavior among academics in higher education to construct a conceptual framework; we examine motivators of online knowledge sharing in HEI. A systematic literature review was performed using a variety of journals across several industries, including higher education. A comprehensive literature search did not turn up any articles that explore or test the association between social capital, knowledge sharing, technology, and quality of education improvement in the HEI. Hence, a need to conduct further research to improve online knowledge sharing behavior and education quality.
\end{abstract}

\section{Introduction}

The literature on knowledge sharing (KS) indicates that effective knowledge management and sharing of knowledge in an organization brings a better quality of education, performance improvement, and the creation of competitive advantage [1,2]. Academic staff at HEIs have a lot of theoretical and practical knowledge, which is one form of knowledge sharing that contributes to highquality education. In addition, the role of the academic staff of higher education is primarily embedded in teaching, conducting research, and supervising students. Therefore, superior knowledge-sharing behavior in their surrounding environment may assist them in the process of developing quality education [2].

In some educational environments, knowledge sharing between academics does not work well because of an inability to share course resources online [3]. Discussions to exchange experiences and teaching studies in the classroom are examples of KS among academics. To achieve a high-quality education system, the HEI requires a good knowledge-sharing platform among academic staff [2]. As reported by [1, 2, 4], the lack of a KS platform is the most important factor affecting the success of the digital knowledge-sharing behavior among academic staff. HEIs are continually working to control resources and expand services [1,2]. Technology is a popular choice among educators because of its benefits in improving educational quality [5].

Another benefit is educational sustainability because technology provides the necessary infrastructure, software, and storage [6-8]. Technology, on the other hand, cannot be a solution on its own. In turn, social capital and technology acceptance provides insights into how individuals access critical resources. Both play a critical role in influencing the actions of organizational members and their KS behaviors [9]. Knowledge sharing in HEI is followed by numerous studies. A systematic review of contributions providing a consistent taxonomy may be useful in identifying opportunities for knowledgesharing behaviors. Literature does not provide a comprehensive picture or sufficient analysis related to the KS behavior of individuals through available technology in HEI. For example, Al-Kurdi [10], limited their study to the empirical evidence of contributions in understanding knowledge sharing in HEIs. Razzaque [11], focuses on the effect of social capital in a virtual environment on innovation mediated by sharing of knowledge and ICT within the healthcare industry.

This paper has two primary objectives. The first is to systematically collect, summarize, evaluate, and synthesize past studies through a systematic literature review. We examine the literature between 2010 and 2020 relevant to social capital and knowledge sharing in the domain of HEI. The second aim is to provide a comprehensive report on the factors used to assess the state of KS through technology and practice in higher education institutions and develop a conceptual framework from the empirical findings of the existing studies in this domain.

Social Capital Theory (SCT) and Technology Acceptance Model (TAM) are two commonly used approaches employed in knowledge sharing research $[6,12]$. The result provides a framework with an extended scope of these theories and additional constructs from literature. Technology serves as a medium to support 
knowledge sharing [13]. This work will help identify opportunities for future research in this area. Knowledge managers can benefit from this study by identifying factors that positively affect the results, allowing them to perform a critical analysis and adapt them to their context.

This study follows the Systematic Literature Review (SLR) method provided by $[13,14]$ to analyze existing literature. This method is suitable for investigating the main characteristics of KS behaviors and the use of technology for KS purposes in HEIs and provides a roadmap for future research to identify relevant issues and challenges.

\section{Related work}

\subsection{Social capital in higher education}

The word "social capital" was coined to describe the relational resources inherent in personal relations that are beneficial to individuals' growth in community social organizations [9]. Social capital has been given significant attention over time, including universities. The concept has been extended to the development of human capital by researchers [2,15] for improving work performance $[4,16]$. Therefore, social capital implies the existence of media, which can be transferred in time and space. Media consist of human-made things (materialized form) and human beings (incorporated form) [2].

This section explores literature related to the theory of social capital, technology, and knowledge sharing in the educational domain. SCT is one of the theories most closely associated with KS research [12]. The fact that these two concepts are discussed together emphasizes the value of knowledge sharing as inherent to educational quality, implying that social interaction between members of academic staff, approached by the social capital theory and technological support, which then become public knowledge within higher education [9].

\subsection{Dimensions of social capital}

Social Capital Theory posits that capital resides in relational networks. Whether knowledge or another form of capital - the network is fed by social relations [9]. Social capital is not a unidimensional concept. Scholars have studied different dimensions of social capital $[5,16-$ 18]. Social capital is often defined in terms of three dimensions: structural, relational, and cognitive. This three-dimensional approach to social capital is beneficial. Many scholars believe that analyzing social capital in terms of its dimensions is a good way to look at knowledge sharing as a social construct $[5,18]$.

Ganguly et al. [19] acknowledged the important role of structural and cognitive social capital in the active exchange of knowledge. Therefore, research on social capital and knowledge sharing has noted the crucial role of social capital in influencing the behavior and opinions of academics when it comes to sharing knowledge $[17,20]$.

\subsubsection{Structural dimension}

The structural dimension of social capital refers to the configuration and pattern of connection between network actors $[8,20]$. It has been analyzed from different angles, from bond strength and significance, network firmness, and scope [21]. The structural dimension centers on social collaboration among academic staff in higher education referred to as associates of the official networks. Nahapiet and Ghoshal [18] believe that the structural dimension of social capital can be conceptualized as "the overall pattern of relationships among social actors - that is, who you reach and how you reach them".

It is unrealistic to assume that academics automatically share knowledge without strong incentives and management support. It is suggested that organizations should link the contribution of knowledge donators by comparing their contributions and the use of a knowledgesharing system [3,22]. Changes in reward systems can lead to changes in the online knowledge-sharing behavior of academics.

Organizational rewards have been proven to be effective in encouraging academics to share knowledge to gain extrinsic benefits [23]. Some researchers have claimed that knowledge sharing is influenced by rewards and incentives $[1,2,4,24]$. The literature argues that management support is the means to create behavioral change in which sharing of knowledge among academics can be encouraged [5]. Therefore, digital knowledge sharing will be most effective when it bridges the gap between donators and receivers.

\subsubsection{Cognitive dimension}

According to Nahapiet and Ghoshal [18], the cognitive dimension refers to "those resources providing shared representations, interpretations, and systems of meaning among parties". It includes attributes like shared vision, goals, values, and languages [5,15,25]. This dimension facilitates shared understanding between individuals, collective goals, and agreed-upon actions between individuals [26].

According to Aslam [5], a shared vision provides a shared reference structure for various organizational associates to assess the reliability and effectiveness of existing organizational expertise and incorporate it into their work routines. Building a shared vision among organizational employees is significant in knowledgedriven organizations in that each employee in the organization can acknowledge and contribute knowledge 
[26]. A communal consideration amongst people, such as a collective language, codes, and vision is all encompassed in the cognitive dimension of social capital $[22,27]$. According to Tsai [28], a shared vision encompasses the communal aims and objectives of the affiliates of an establishment. In addition, it encourages common insight and interchange of thoughts.

Shared goals can be accomplished within an organization through collaboration and knowledge sharing. Within the university, knowledge exchange helps to bring individual knowledge to the attention of the whole community and to work for a shared goal [15]. It should be noted that a lack of shared goals or having incompatible goals can hinder knowledge sharing. Smith [29] found that "individual members of academic institution place a higher priority on individual scholarly achievement and teaching than on sharing common visions toward organizational goals and objectives".

\subsubsection{Relational dimension}

The relational dimension impacts the individuals' drive to exchange their knowledge with others. The readiness or inspiration to exchange will be greater when workers trust and recognize each other [30]. Lee [4] and Tsai [28] noted that trust could lead to better knowledge sharing. Tsai [28] concluded that if management does not support the interpersonal relationships of a group, it will weaken trust and more so create distrust, which will ultimately have a detrimental effect on such interactions and the prospects for the acquisition of knowledge, knowledge generation, and knowledge exchange.

Trust is essential within the knowledge exchange environment because people probably share knowledge with colleagues when they observe others, to be honest. Tsai [28] discuss that inside the organizational environment, diverse means of trust (such as affect-based trust, mutual trust, interpersonal trust, and identificationbased trust) have proven to enable complicated knowledge exchange, from the viewpoint of the pair of knowledge recipients and knowledge contributors.

\subsection{Technological factors and knowledge sharing}

Three major technological factors influencing online knowledge sharing are identified here including the availability of IT infrastructure, perceived ease of use, and perceived usefulness [3, 31-33]. In this study, online knowledge sharing refers to the process that can enable academics to share digital resources (teaching materials, research outputs, and best experience) using existing systems. Therefore, in this study context, digital knowledge sharing and online knowledge sharing are used as interchangeable terms. To promote knowledge sharing, a knowledge-sharing system should have sufficient functions with excellent usability, user-friendliness for retrieval, and versatility in meeting needs to facilitate online knowledge-sharing activity [33]. The higher the standard of the knowledge-sharing system, the more knowledge would be exchanged by workers within an organization [33]. Employees use a variety of social networking technologies to connect and share knowledge with coworkers and other communities of practice.

The presence of IT infrastructure enables the use and exchange of computerized information systems in an enterprise. It could include hardware, software, network, and communication infrastructure [34]. Provisions of IT infrastructure play an important role in the process of sharing knowledge and accelerating the pace of knowledge creation. Technological infrastructure helps in creating knowledge repositories IT infrastructure facilities may expand the use of software and hardware in knowledge sharing, as well as assist academic staff in effectively creating, transferring, and sharing knowledge. The provision of IT facilities in higher education will increase lecturers' desire to share their knowledge [35]. According to Al-Busaidi and Olfman [31], a good IT infrastructure will greatly support the knowledge-sharing process. The research attempts to evaluate the use of IT in KS based on TAM [3,12,20]. According to Davis [36], improvements in ease of use will lead to improvements in performance. Perceived ease of use is a motivator in applying information technology in knowledge sharing behavior $[4,20,31]$. This suggests that people who know how to use all of the features of an online system are more likely to communicate. Employees who do not know how to work or post materials, on the other hand, may not want to contribute knowledge.

Employees' perceived usefulness of IT for KS [3,6] offers diagnostic lenses for determining how actual usage and intention to use are affected. Perceived usefulness is identified as a determinant of online knowledge sharing [6]. Davis [36] explains that employees would have a good feeling if they assume that sharing their experience online would most likely lead to better outcomes. Perceived usefulness is believed to be a motivator in the TAM $[28,36]$ driven by near-term and long-term results.

\section{Search methodology \& approach followed}

This research employed a systematic review of literature related to the theory of social capital, technology, and knowledge sharing in the context of HEI. A systematic review is a well-planned review to answer specific research questions using a systematic and explicit methodology to identify, select, and critically evaluate the results of the studies included in the literature review [14]. In contrast to the traditional or narrative review, systematic reviews use a more rigorous, well-defined 
approach to review the literature in a specific area [13]. When writing a literature review, the author's main goal is to bring the reader up to date on the literature on a specific area as well as justifying future research [14].

This literature review focuses on the four relations depicted related to social capital: Social Capital Theory, knowledge sharing, ICT, and KS capacity/ quality of education. It shows that social capital resources and relationships are capable of improving the quality of education and the use of ICT. The use of ICT is predominantly referred to in this study as the behavior of an individual who shares knowledge to grasp new knowledge from the social capital of resources stored within the university knowledge repository or among the academic staff through the available technology. The approach proposed by $[13,14]$ was selected for this study (Figure. 1). It consists of four main phases. Each phase contains several steps. The first stage, planning, is composed of two key components, research questions, and search strategy, both of which are designed to supplement any current research's comprehensive theoretical questions. The second stage, selection, involves sorting and extrapolating the data. This data processing exercise is composed of data collection followed by data refinement. The third stage, extraction, evaluates the data by applying rigorous assessment criteria. Finally, the fourth stage, data synthesis, involves a step-by-step analysis of data to produce a concluding set of subsequent procedures.

\subsection{Planning}

\subsubsection{Research Question}

This study aims to search and assess articles published from 2010 to 2020 concerning identifying factors to KS behavior of individuals using technology for KS purpose in HEI. The following questions have been formulated:

Do social capital and technological factors affect digital knowledge sharing in HEI? This question aims to offer an up-to-date picture of the current status within the existing research focusing on studies that consider the use of technology for KS with social capital and technological factors to examine KS behaviors of academics in HEIs. What appropriate conceptual framework should be constructed for the success of digital knowledge sharing in HEI? Answering this question can be used to create an appropriate framework by highlighting enabling factors behind the KS behavior of academic staff in HEI, which are obtained from empirical evidence.

\subsubsection{Literature Search Procedure and Criteria}

Detailed analysis of the search strategies used is described in search terms and literary sources as follows:

\section{Constructing Search Terms:}

Having defined the objective and the database to be used, the next step was the collection of the material to be analyzed. To identify articles that dealt with Social Capital, technology, and KS in HEI contexts search terms were devised using a set of pre-defined definitions and methods $[13,14]$.

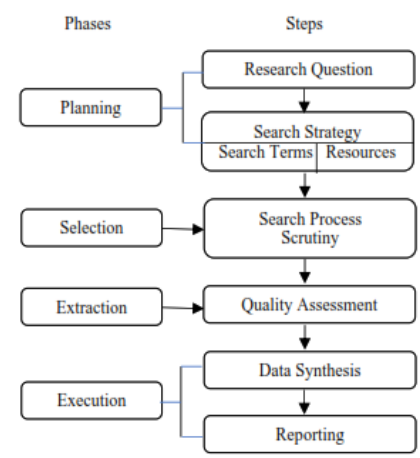

Figure 1: The review protocol. Adopted from [13, 14]

They were then used to create the following search strings: the Boolean operator "OR" was used to provide alternate meanings, and the Boolean operator "AND" was used to ensure that any combination of the terms that could be searched include KS in higher education.

All research terms were obtained from the topic being investigated. These terms are KS, Social capital, technological factor, and higher education. The final search terms were as follows: ([("knowledge exchange" OR "knowledge sharing" OR "knowledge flow") AND ("social capital") OR "technology acceptance model"] OR ["Higher education"]) was the final search word.

Literature Search sources:

As the aim of this study is to develop a conceptual framework for understanding online knowledge sharing behavior in HEI and identifying future research opportunities based on the existing studies. The method fits with the aim of this study, which is to create a comprehensive picture from a heterogeneous collection of interdisciplinary research conducted in different contexts with various research designs. Papers were initially identified by searching in Google Scholar. The Mendeley reference management tool was then utilized for management and sorting to preserve relevant search results and removed replicated articles.

\subsection{Selection}

\subsubsection{Study Selection Process}

This phase of the systematic literature review protocol shows the method for selecting and recognizing the studies that are most relevant to the defined research questions. Figure. 2 outlines the steps of this process. 
In search stage one from the electronic databases resources were systematically searched, and based on the initial search term, 84 studies were found through automatic searches. The criteria to verify the pertinence to the scope of the research used by the authors in this first selection process were: (1) The identification in the article of the use of the Social Capital theory or technological factors, and; (2) The keywords must be associated with $\mathrm{KS}$ in higher education.

In search stage two, the titles and abstracts were assessed for relevance, and the contents were briefly scanned to ensure relevance to the issues under investigation, and the duplicated studies were removed through the Mendeley reference manager. After removing the duplicates, a total of 73 studies were included. After that, the papers were included based on the predefined inclusion and exclusion criteria (Table 1) for the abstract and conclusion of each article. In this analysis, 27 articles were discarded for not being pertinent to the scope of the research, leaving 46 articles. The next selection process was carried out to analyze the content of the articles as a whole, mainly those where it was not clear from reading the abstract whether the article was pertinent to the scope of the research by applying the predefined quality assessment criteria. After this reading, 16 articles were discarded, resulting in 30 articles to be analyzed in this research.

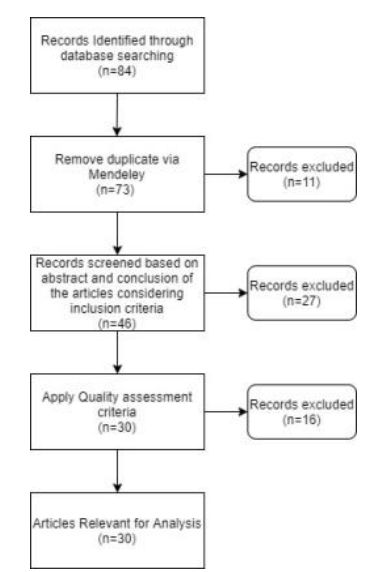

Figure 2: Phases and steps of the systematic review

\subsubsection{Scrutiny and Filtering Process}

The purpose of applying inclusion and exclusion criteria is to make sure that all chosen primary studies in the systematic literature review are the most appropriate and are relevant to the study to answer the research questions in an SLR. The research articles from journals and conferences proceedings are written in the English language and published from 2010 to 2020 in online digital databases. This provided a continuous period from 2010 to 2020 and an understanding of KS and systematic conclusions from recent relevant materials. Articles that do not relate to KS and social capital or technological factors were eliminated. Articles that were unsuccessful in attaining any of their objectives were excluded. Manuscripts not presented entirely in English were excluded. Finally, research articles unrelated to the research questions were removed.

Table 1: Inclusion/exclusion criteria

\begin{tabular}{|l|l|}
\hline Inclusion Criteria & Exclusion Criteria \\
\hline Papers that are written in English & $\begin{array}{l}\text { Papers that are written other } \\
\text { than the English language. }\end{array}$ \\
\hline $\begin{array}{l}\text { Paper that addressed KS and } \\
\text { social capital or/and technological } \\
\text { factors. }\end{array}$ & $\begin{array}{l}\text { Papers that do not explicitly } \\
\text { discuss KS and Social capital } \\
\text { or technological factor. }\end{array}$ \\
\hline $\begin{array}{l}\text { Paper published between 2010 to } \\
2020\end{array}$ & $\begin{array}{l}\text { Paper that published after or } \\
\text { before 2010 to 2020 }\end{array}$ \\
\hline $\begin{array}{l}\text { Studies that directly or indirectly } \\
\text { address the research question. }\end{array}$ & $\begin{array}{l}\text { Studies that are not relevant to } \\
\text { the research question }\end{array}$ \\
\hline
\end{tabular}

\subsection{Extraction Study}

\subsubsection{Quality Assessment}

The Quality Assessment (QA) method was used to evaluate the quality of the primary studies, which is considered important for the evaluation of included articles [13]. The overall goal of QA is to make decisions about the general content of the papers included. Three quality assurance criteria were established for the proposed paper, as described below.

QA1: Does the research paper considers social capital theory or technological factors for KS in HEI?

QA2: Is there a sufficient description of the research methodology in the included study?

QA3: Are the objectives and findings clearly in the primary study?

Each of the articles was assessed on the abovementioned QA criteria and given a high, medium, or lowquality rating. The article scored 1 or 0 for satisfying or not satisfying the criteria. Papers with a score of 1 were considered high-scoring, thus more important and papers with a score of 0 were considered low-scoring and less relevant. After applying the above criteria, it was found that 16 papers did not fulfill the criteria; therefore, these studies were excluded. A total of 30 papers are considered as the primary materials for the review.

\subsection{Execution}

\subsubsection{Data extraction and synthesis}

The data extraction and synthesis took place by studying each of the 30 papers and extracting relevant data via Mendeley and MS Excel spreadsheets. The overall goal of this stage was to design data extraction forms to accurately record data from the initial research [13]. Therefore, for the analysis of the articles, a criterion was 
drawn up with the main aspects to be observed in each of the articles, which are classified as follows: reference; method; model and theory; as well as objectives and results found. The reference contains the name of the article in which the study was published and the year of publication. The method concerns the approach followed - quantitative, qualitative, or mixed and the sample characteristics, such as the type of industry studied, and the countries where the data was collected. The model, and theory, include the research theoretical lens and the main concepts the authors used as a base for the literature review. Finally, the objective and results include content analysis of the objective and results of the selected thirty articles.

\section{Results}

To address the above question, a literature taxonomy aimed at summarizing the existing research was created. The final sample of 30 papers was read and studied to obtain a detailed picture of the existing research. This section presents the descriptive analysis of the articles.

Analysis of the study area of the research verified that the theory of social capital has been used in various research areas including HEI across various countries. In this research, two categories were used to analyze the study area: Higher Education Institution (HEI) and Business Organization. The result indicates $73 \%$ of the articles conducted were in HEI while $27 \%$ of the conducted in business organizations (Figure 3). SCT is conducted in different countries with various contexts (Figure 9). However, several studies identified in the literature sort utilized social capital theory with and technological factors for knowledge-sharing purposes. In particular, none of the papers identified in this work examined the use of SCT and the identified technological factors to explore the utilization of technology for knowledge sharing in HEI.

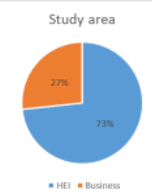

Figure 3: Distribution of Articles per study area

Concerning the results obtained by the articles analyzed, among those that aimed to examine the issue of performance jointly with $\mathrm{SC}$, some results stand out.

The study by [25] and [15], indicates the influence of the three dimensions of SC in the integration of knowledge and consequent improvement in academic performance. Work in [40] also emphasizes the structural properties (structural component of SC) and its relationship with productivity in their study. According to Lee [4], the team's SC affects knowledge sharing and, as a result, indirectly leads to performance enhancement. However, conditions must be satisfied for changing the behavior of academics to become actively involved in knowledge sharing via technology. These conditions are the existence of incentives, and the ability to combine knowledge or experience [18]. The impact of these conditions occurs through the three dimensions of Social Capital $[18,25]$. This study made use of and adapted [18] classification of the social capital dimensions.

\subsection{Use of social capital and technological factor for digital knowledge sharing in HEI}

Table 2 shows the journals and conferences in which the papers selected for the SLR appeared. The journals that publish articles on this area are well-distributed. The 30 journal articles and conference papers are divided into several social capital theory and technological factor categories (Appendix, Table 3). This indicates that the subject in question is of interest in various areas. Figure 4 shows the distribution of articles over time, from 2010 to 2020. Observing this figure, we can identify that the existence of publication every year from 1 to 4 . This shows continued interest in examining the integration of social capital and technological factors for digital knowledge sharing in higher education.

Some studies mention more than one, but not all three dimensions of social capital (Figure 5). The relational dimension appears in 88 percent of the articles selected; it was the most dimension used most often in the article reviewed. The second most common dimension is the structural dimension which was cited in 84 percent of the articles selected. Finally, the cognitive dimension was found in 69 percent of the articles analyzed. All three dimensions were used together in 13 articles (Figure 5).

A consensus was not identified about the social capital dimensions that have the most impact on KS. A study by [29] mentions the Relational dimension is important for the KS operation, and the cognitive dimension is a predictor for the quality of knowledge sharing. In turn, [41] emphasizes the facet of identification contained in the Structural dimension as having the greatest effect on knowledge sharing.

There are a variety of terms used to refer to $\mathrm{KS}$, to facilitate understanding, the following terms were grouped to the process of "knowledge sharing", due to how they were utilized: exchanging knowledge, transferring knowledge, and knowledge flow. Other different terminologies that refer to the quality of education were identified. To facilitate understanding, the following terms were grouped to the process of "quality of education", due to how they were utilized: academic performance, teaching performance, work performance, organizational performance. 
Table 2: The number of articles analyzed per journal

\begin{tabular}{|l|c|l|}
\hline \multicolumn{1}{|c|}{ Journals } & $\begin{array}{l}\mathbf{Q} \\
\text { ty }\end{array}$ & $\begin{array}{l}\text { Journal } \\
\text { Type }\end{array}$ \\
\hline International Journal of Knowledge Management & 1 & Journal \\
\hline Technology Analysis and Strategic Management & 1 & Journal \\
\hline Journal of Librarianship and Information Science & 1 & Journal \\
\hline $\begin{array}{l}\text { VINE Journal of Information and Knowledge } \\
\text { Management Systems }\end{array}$ & 1 & Journal \\
\hline $\begin{array}{l}\text { 13th International Conference on Knowledge } \\
\text { Management and Knowledge Technologies }\end{array}$ & 1 & $\begin{array}{l}\text { Confere } \\
\text { nce }\end{array}$ \\
\hline Journal of Behavioral and Applied Management & 1 & Journal \\
\hline Electronic Journal of Knowledge Management & 1 & Journal \\
\hline Journal of Knowledge Management & 2 & Journal \\
\hline International Review of Administrative Sciences & 1 & Journal \\
\hline Journal of Engineering and Applied Sciences & 1 & Journal \\
\hline UKM Journal of Management & 1 & Journal \\
\hline Education and Information Technologies & 1 & Journal \\
\hline Administrative Sciences & 1 & Journal \\
\hline International Journal of Information Management & 2 & Journal \\
\hline $\begin{array}{l}\text { International Journal of Distance Education } \\
\text { Technologies (IJDET) }\end{array}$ & 1 & Journal \\
\hline Mediterranean Journal of Social Sciences & 1 & Journal \\
\hline $\begin{array}{l}\text { 2016 International Conference on Information } \\
\text { Technology Systems and Innovation }\end{array}$ & 1 & $\begin{array}{l}\text { Confere } \\
\text { nce }\end{array}$ \\
\hline SAGE Open & 1 & Journal \\
\hline Journal of Applied Business Research (JABR) & 1 & Journal \\
\hline $\begin{array}{l}\text { International Journal of Environmental Research } \\
\text { and Public Health }\end{array}$ & 1 & Journal \\
\hline African Journal of Business Management & 1 & Journal \\
\hline International Journal of Educational Management & 2 & Journal \\
\hline Journal of Innovation and Entrepreneurship & 1 & Journal \\
\hline $\begin{array}{l}\text { The International Journal of Higher Education } \\
\text { Research }\end{array}$ & 1 & Journal \\
\hline Library Review & 1 & Journal \\
\hline Journal of Humanities and Social Sciences, & 1 & Journal \\
\hline $\begin{array}{l}\text { International Journal of Business and } \\
\text { Management }\end{array}$ & 1 & Journal \\
\hline & & \\
\hline
\end{tabular}

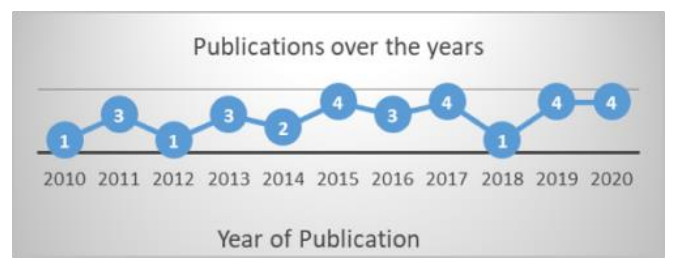

Figure 4: Study distribution over the given years

The theory of social capital was used in the twentyseven articles in combination with other theories or stand-alone. Six additional models or theories were used, as detailed in Figure 6. A connection between the theories of social capital is observed concerning relations between individuals, as in the Technology Acceptance Model. According to the literature, studies that combine SCT and TAM account for $7 \%$ of the total, while papers that only use SCT account for 43\%. (Figure 6). This demonstrates the need to combine SCT and TAM for a deeper understanding of technology as well as relational and behavioral changes to use technology for KS in HEI.

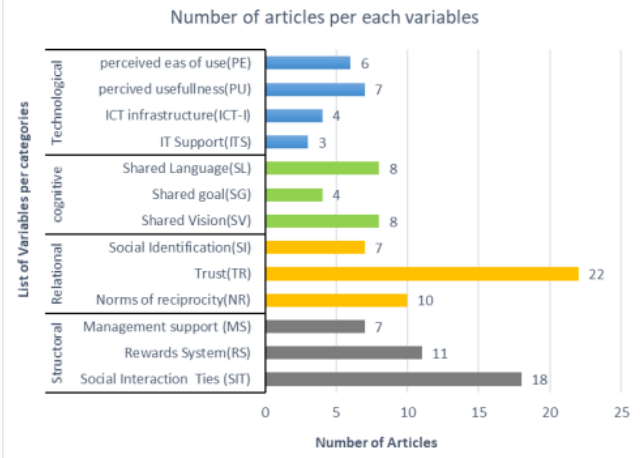

Figure 5: Distribution of Variables per Articles

The methods used are shown in Figure 7. The review reveals that $83 \%$ of articles used quantitative methods, $14 \%$ used qualitative methods, and 3\% used mixed methods in their empirical study. This shows that studies are more focused on the quantitative method while less concentration is given to qualitative research methods. Based on this systematic literature review, few qualitative methods examine KS behavior of academics with social capital theory and TAM model. In addition, regarding methodological choice, there is no agreement among the literature. According to Koranteng and Wiafe, [25] quantitative is more reliable when the research deals with a larger population and quantifiable data. In contrast, Diriye [16] mentioned that the qualitative research method is useful when the research deal with interpreting the organizational environment and studying human behavior. Therefore, we can conclude that the reason why most of the studies conducted around social capital theory and TAM deals with testing hypotheses rather than producing theory requires further empirical investigations.

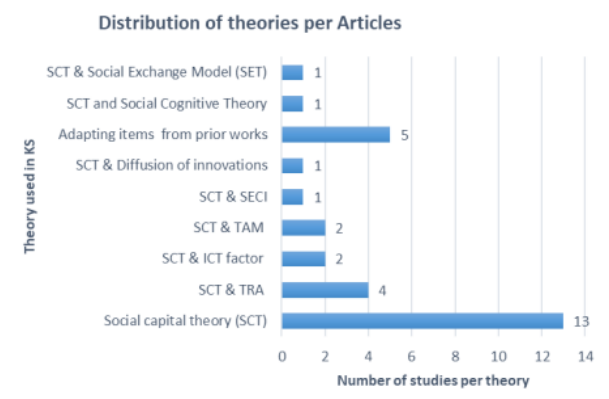

Figure 6: Distribution of Theories per articles

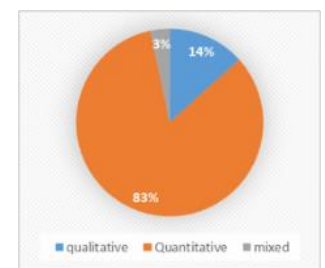

Figure 7: Distribution of Methods used 
Studies conducted by country are presented in Figure 8. Articles on the topic have been published in more than 17 countries. This demonstrates that some countries place a lower priority on SCT. As a result, the cultural differences in KS in different countries, which can have a major effect on people's attitudes toward KS, must be taken into account.

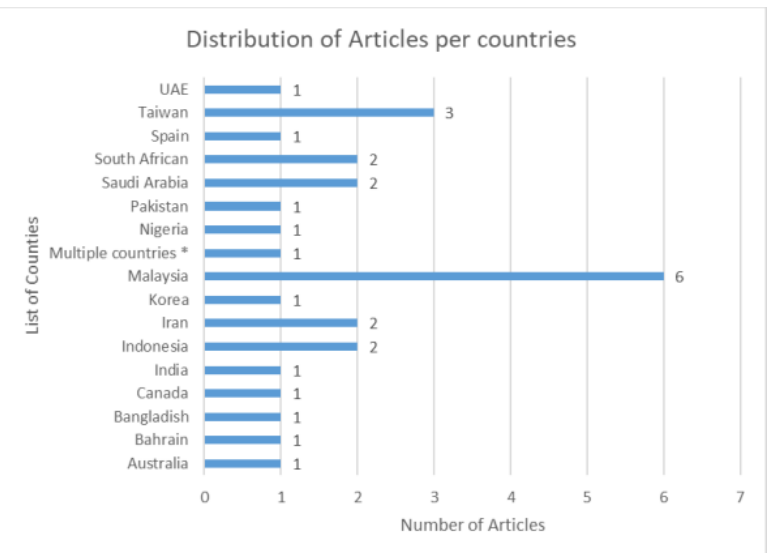

Figure 8: Distribution of Articles per country

It can be concluded that social capital theory and TAM are well suited for this study. Fari [12] confirms the relevance and appropriateness of the use of Social Capital and the TAM to understand the various complementary factors, social and technological factors for effective knowledge sharing. Overall, the results demonstrated that the adoption of social capital theory and TAM to investigate the KS behavior of individuals in HEIs can be considered for future research.

\subsection{Conceptual framework for the success of digital KS among academic staff}

Factors for effective digital knowledge sharing with no time and place restriction organizations and intensive use of knowledge are growing more common. The global economy and massive technology use transform knowledge into an even more valuable and strategic component, which makes the management of this knowledge essential for the success of organizations. The motivation of organizations in carrying out $\mathrm{KS}$ is to promote improvements in business performance, which needs an efficient KS platform [6].

Research by [42] stresses the importance of network relations as an important function to feed the SC of organizations to generate and exchange knowledge. The importance of management support as a motivator and facilitator of $\mathrm{KS}$ is highlighted in the study, which includes the need for an explicit incentive for members to share their knowledge [43].

Concerning social capital theory and/or technological factors used to investigate $\mathrm{KS}$ in higher education institutions, cognitive social capital refers to "those resources providing shared representations, interpretations, and systems of meaning among parties". It includes attributes like shared vision, goals, reciprocity, trust, and beliefs [8,18,25]. Authors conceptualized the structural dimension of social capital in different ways. A study by [41] considers the structural dimension, constructs concentrate on a strong network tie structure and the resources that are embedded within that structure. Although social capital has been shown to assist the transfer of knowledge within HEI, the link between social capital and the technological factor used to share knowledge in terms of the factors which facilitate or inhibit the sharing of knowledge is not well established [1]. The difficulty in finding meaningful definitions and classifications of knowledge and social capital applied across settings is a challenge [2,15,25].

Concerning technological factors for knowledge sharing, the literature argues that employees' technical skill on how to operate the IT tools or system is an important asset in the organization [30,38]. Many organizations use KM, such as KS, information capture by technology, as one of the methods to offer to save the knowledge. In this case, technology plays a significant role in the implementation of KS in a business. A study by [3] Explained that when workers think the technology can be used easily, it is more likely that they will present their expertise. In this case, when the academic staff feels technology is easy to use for sharing their knowledge, they will be motivated to share their knowledge anytime and anywhere. So, to successfully implement knowledge sharing among academics through the website, the academics must know about the website technology, the perceived usefulness of the website technology, and perceived ease to use of website technology. This promotion of knowledge sharing through IT in line with social capital was evident in several empirical studies $[7,12,30,38]$.

These authors commonly concluded that IT support and infrastructure were secondary to trust in $\mathrm{KS}$. In other words, IT cannot alone achieve effective knowledge sharing in the absence of factors such as trust and management support. Therefore, management plays an important role in selecting the correct technology to fit the existing organizational culture [28].

Others argue ICT can facilitate access to knowledge stored in databases to improve explicit knowledge sharing in organizations. ICT promotes knowledge sharing by providing effective communication channels and identifying the source of knowledge. According to [30] the key issue, however, is to choose and implement a suitable technology (easy to use) that provides a close fit between people and organizations because Technology that works effectively in some organizations may fail in others. Since some people are unfamiliar with the system and procedure, ICT can often serve as a 
possible obstacle. In general, the literature suggests that ICT is related to knowledge sharing [3,6,12,31].

Although a variety of literature used different categories of measurement in these three social capital dimensions. For example, Diriye [16] used Trust as a relational and reward system as structural dimension measurements. Some others used social interaction as structural; norm, social interaction, and trust as relational [25]. Based on this the current literature found that the facets of Reciprocity (NR), Trust, Identification belongs to the relational dimension; social interaction (SI), Reward system (RS), management support (MS) belong to the structural dimension, and the facet of shared vision, shared goal, shared language belongs to the cognitive dimension, stand out as being frequently mentioned. According to the SLR, the most common usage of these facets is relevant to the current study background.

Besides, most researches identified in the literature indicate that the factors that influence the use of technology for KS are perceived usefulness of website technology which refers, the degree to which staff believes that using a particular system will be enhanced to share knowledge [3]. In this case, the academic staff may assume that by using the specific system, i.e., website technology, knowledge transfer and sharing among lecturers would be enhanced [3]. Furthermore, perceived ease of use of website technology refers to how confident employees are that using a specific system would enable them to exchange knowledge with minimal effort. In this case, the academics believe that using the website technology would be free of effort to transfer and share their knowledge among other academics [3]. Therefore, this paper suggested that perceived usefulness, perceived ease to use, and availability of IT infrastructure can be used as future research to investigate KS through website technology.

Finally, based on the results of the study, it was discovered that the majority of the studies have a connection between the two key topics of improving educational quality and sharing knowledge. Both objectives have an important practical contribution to the universities, since discussions on the quality of education and $\mathrm{KS}$ are recurrent among managers and, as pointed out by [37], the sharing of knowledge is seen as a generator of new ideas. The joint research on Social Capital with knowledge sharing is significant, for, as already indicated by [5], the skill at recognizing new knowledge and assimilating it is essential for organizational learning and innovation. Technology supporting network ties is the key in the sharing of knowledge; as people interact and share, they absorb and apply this shared knowledge, generating new knowledge. Finally, the following framework (Figure 9) can be used for further empirical investigation.

The conceptual framework shown in Figure 9 encourages the intention to share knowledge which also leads to actual digital knowledge sharing behavior; the technological factor encourages the intention of academics for technology used for digital knowledge sharing. This, in turn, promotes the standard of education within HEI. Thus, the technology reflects the organizational technological ties, which are facilitated by the KM processes that are: knowledge acquisition, knowledge conversation, knowledge application, and knowledge protection [44]. As a result, knowledge sharing enhances the quality of education for HEI $[6,8,19,22]$.

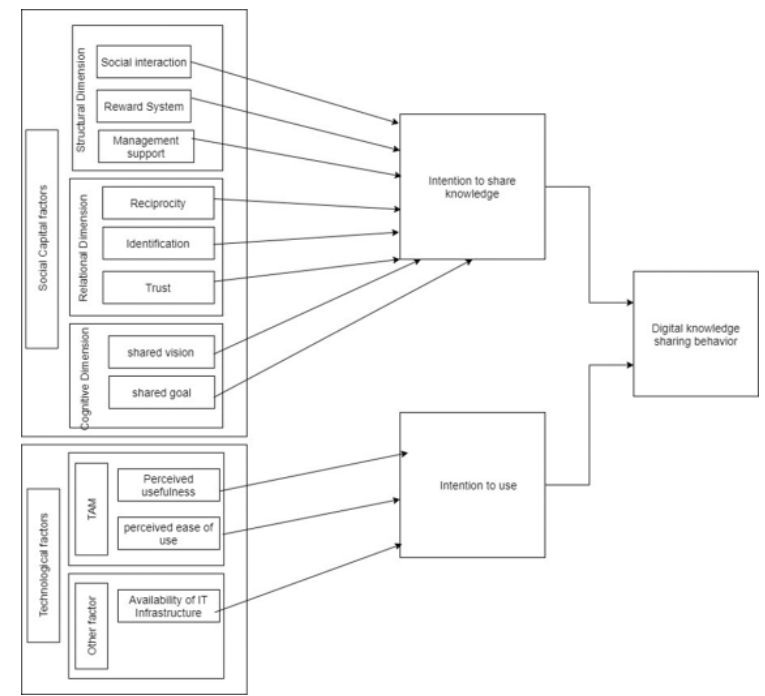

Figure 9: a proposed conceptual framework for KS behavior of individuals

\section{Discussion}

Outcomes of this research provide a current view of KS behavior for individuals in HEIs. Studies consider the use of SC supported by technology in HEIs, thus forming the basis of improving the use of technology for $\mathrm{KS}$ purposes from which universities may benefit. This analysis may also be useful for researchers working to identify characteristics of KS behaviors based on a willingness to incorporate current technology into the teaching process and research activities of HEIs, as well as the factors that affect the full use of technology for KS in HEIs.

Thus, to understand the knowledge-sharing behavior within HEI, additional scholarly work is required to identify the social capital and technological factors which facilitate or inhibit an individual's intention to share knowledge in a University, specifically Ethiopian universities. To the content dealt with, the following research opportunities were identified:

- Focus on the management support;

- Measuring of the impact of KS via technology for quality of education; 
- Use of technology as a channel for knowledge sharing;

- Different combinations of social capital

dimensions;

- Impact of the human factor.

The relationship between knowledge-sharing behavior and the dimensions of social capital for successful organizational knowledge sharing has been stressed in several organizational contexts [5,15-18]. They are useful in explaining and predicting the sharing of knowledge by influencing the conditions necessary for knowledge and resource exchange and combination to occur. The role of social capital in the ICT intervention context is also discussed in several studies [1,2,4,25]. However, most of them discussed the effect of adopting ICT on KS. Focusing on the questions like identifying factors on how to use the existing technology for $\mathrm{KS}$ purpose considering social capital theory for the improvement of KS behavior of individuals via technology in HEI is missing in the works of literature. This gap is an opportunity for future research; the current level of investigation shows the need for more attention to investigating the factors that influence the KS behavior of individuals in HEIs.

The conceptual framework provided by SCT, TAM, and other related technological factors will help analyze the behaviors of academics on knowledge sharing using web technologies. Therefore, this review reflected the theoretical models and the factors used to assess the existing state of the study. The research used the findings from 30 studies: 28 were found in journals and 2 were obtained from conferences proceedings. Based on the SLR, the research questions were answered and presented along with specific themes: motivations (or reasons) behind the use of social capital and technological factors in HEIs, theoretical models, and factors that may inhibit or prevent the use of technology for KS in HEIs.

\section{Conclusion}

This research presents an analysis of the state of the discipline of KS in an HEI context, analyzed in the light of Social Capital Theory and technological factors. The relation between these two topics is relatively new. The SLR revealed that there is limited empirical evidence to support social capital theory with technological factors which investigates using a qualitative method in the HE context. The majority of the papers identified merely focused on the effect of specific factors on KS $[15,16$, 50 , and 51]. Some studies reported having social capital factors with emerging technological factors [1, 2, and 4]. The studies that investigated the subject of technology have frequently focused on the usefulness of the technology and have tended to exclude human aspects, such as to what extent the existing technology is utilized/used for its intended purposes within HEI and how difficult is the system to use for KS purpose within HEI. Thirteen of the articles identified investigate KS having social capital with objectives quality of education; five articles discussed innovation capacity.

The study reveals several interesting issues related to the use of social capital and technological factors affecting the KS behavior of individuals using technologies for $\mathrm{KS}$ purposes. Outcomes range from improving individual innovation to enhancing the overall quality of education. This work also identified some theories used across studies. It was surprising to discover that few research studies examine social capital and technological factors in HEI contexts. Based on the SLR, most of the studies $90 \%$ of them use a quantitative method with various contexts. This shows there is a lack of studies that investigate using the qualitative method. Future research can address this gap within the HEI context. Such research could provide a broader picture of KS behaviors for using technology to improve the overall knowledge sharing practices in HEI and improve the overall quality of education in these institutions.

Therefore, this study offers as a main theoretical contribution of the state of the discipline of knowledge sharing in higher education. This study develops a Digital knowledge sharing framework based on the identification of contextual factors from different social capital dimensions and associates with various technological factors (like availability of ICT, perception of easy to use, and perceived usefulness) to demonstrate the key motivators of digital knowledge sharing in higher education. This proposed contextual link seeks to resolve inconsistent findings around the research of utilizing technological resources for the improvement of knowledge-sharing behavior of academics within higher education. Therefore, the framework can be used as a guideline for future researchers who wish to examine digital knowledge sharing in higher education. And allow us, to confirm the usefulness of the proposed framework in enhancing Knowledge sharing using ICT in higher education.

\section{Reference}

References were removed due to publication page limitations. A full reference list is available upon request from the authors 